\title{
WASTES IN THE SYSTEM OF CIVIL RIGHTS OBJECTS
}

\author{
Anna A. Kisel \\ Belarusian State University of Economics, Minsk, the Republic of Belarus
}

Introduction: the article presents the general properties of waste and their place in the system of civil rights objects. In the modern conditions of society, when the dynamics of developing the relations has an indisputable sign of globalization, it seems expedient to address certain civil law institutions as structural elements of a system having certain characteristics. The consideration of the concept of "waste" in the system of civil rights objects as an established order in the order and connection of actions or as a set of constituent parts homogeneous in terms of their tasks, will subsequently allow identifying the problems in the civil law regulation of waste management in the Republic of Belarus and developing measures to eliminate them. Methods: there are used the general scientific methods of research, such as analysis, synthesis, comparison, as well as the private scientific methods of research such as formal and legal, technical and legal ones. Results: the author investigates the correlation of the category "waste" and the category of "civil objects" used in the Civil Code of the Republic of Belarus. Conclusions: the author identifies the main criteria for classifying wastes as objects of civil rights. The position on referring wastes to the category of things is stated due to the presence of physical characteristics as a substance or item, as well as the presence of the goal to both refer wastes to the resource category, and to strive for the benefit by minimizing the negative impact on man and the environment, and also by establishing the order of compensation for the harm caused.

Key words: civil rights system, object of civilian circulation, things, objects, waste, resources.

УДК 347.1

ББК 67.404.1

\section{ОТХОДЫ В СИСТЕМЕ ОБЬЕКТОВ ГРАЖДАНСКИХ ПРАВ}

\author{
Анна Антоновна Кисель \\ Белорусский государственный экономический университет, г. Минск, Республика Беларусь
}

Введение: в статье рассматриваются общие свойства отходов и их место в системе объектов гражданских прав. В современных условиях существования общества, когда динамика развития отношений имеет бесспорный признак глобализации, целесообразным представляется обращение к отдельным институтам гражданского права именно как к структурным элементам системы, обладающим определенными характеристиками. Рассмотрение понятия «отходы» в системе объектов гражданских прав как устоявшегося порядка в расположении и связи действий либо как совокупности составляющих частей, однородных по своим задачам, в последующем позволит выявить проблемы в гражданско-правовом регулировании обращения отходов в Республике Беларусь и выработать меры по их устранению. Методы: использованы общенаучные методы исследования, такие как анализ, синтез, сравнение, а также частнонаучные методы исследования: формально-юридический, технико-юридический. Результаты: автор исследует соотношение категории «отходы» и используемой в Гражданском кодексе Республики Беларусь категории «объект гражданских право$\sim$ отношений». Выводы: автором определены основные критерии отнесения отходов к объектам гражданских 록 прав. Изложена позиция по отнесению отходов к категории вещей в силу наличия физических характеристик как вещества или предмета, а также присутствия целеполагания как в отнесении отходов к категории ресурсов, так и в стремлении к благу в виде минимизации негативного воздействия на человека и окружающую среду, а также путем установления порядка возмещения причиненного вреда.

Ключевые слова: система гражданских прав, объект гражданского оборота, вещи, предметы, отходы, ресурсы. 


\section{Введение}

В современных условиях существования общества, стремительно развивающегося и осваивающего результаты четвертой промышленной революции, целесообразным представляется обращение к отдельным институтам гражданского права как структурным элементам, обладающим определенными свойствами и обеспечивающим целостность системы гражданских правоотношений.

Во-первых, анализ понятия и содержания системы объектов гражданских прав предоставляет возможность обосновать место отходов в структурно упорядоченной совокупности дозволенного поведения, возможностей требования определенного поведения и принятия мер правоохранительного характера.

Во-вторых, рассмотрение всякой системы как устоявшегося порядка в расположении и связи действий либо как совокупности составляющих частей, однородных по своим задачам, позволяет определить общие свойства отходов как объектов гражданского оборота.

В-третьих, анализ юридически значимых и законодательно закрепленных признаков отходов является способом выявления проблем в гражданско-правовом регулировании обращения отходов в Республике Беларусь.

В-четвертых, установление причин наличия правовых коллизий в области обращения с отходами служит основой для выработки мер по их устранению и создает условия для обеспечения и реализации на практике конституционного права каждого на благоприятную окружающую среду.

\section{Понятие «система объектов гражданских прав» в различных теоретических исследованиях}

Гражданский кодекс Республики Беларусь не содержит нормы, определяющей, что представляет собой система объектов гражданских прав. Данным нормативным правовым актом определен лишь перечень объектов, который нельзя считать исчерпывающим в силу наличия указания на иное имущество. Данная отсылка позволяет законодательно регулировать общественные отношения, которые возникают на каждом новом этапе развития общества, в частности по поводу тех объектов, о существовании которых ранее не шла речь, но их наличие при современном научнотехническом прогрессе неизбежно.

Для обеспечения более совершенной правовой регламентации гражданских правоотношений с учетом изложенного целесообразно обратиться к теоретическим понятиям, в частности определению сути и содержания системы объектов гражданских прав.

По мнению Н.С. Михайловой, «под системой объектов гражданских прав следует понимать не всякое перечисление предметов и явлений, относящееся к системе гражданского права, а необходимое целесообразное, структурно упорядоченное объединение, в котором места составных частей определены обобщением юридически значимых признаков, свойств и качеств» [8, с. 177]. Данное определение на первое место выводит характеристики самих объектов, закрепленные нормативно, что раскрывается через термин «юридически значимые».

При этом Н.С. Михайловой подвергается критике концепция В.А. Витушко, построенная, по ее мнению, первоначально на «соотносимости понятия объекта с интересами субъектов правоотношений» [8, с. 178]. Допуская «традиционное подразделение объектов на объекты вещных правоотношений, спорными и не всегда ясными выглядят утверждения о бесконечности числа, видов, типов объектов гражданских прав» [8, с. 178].

Вместе с тем именно позиция В.А. Витушко дает возможность подойти к классификации объектов гражданских прав с различных теоретических позиций и обосновывать место отходов в системе гражданских прав. Утверждение последнего о бесконечности числа и видов позволяет утверждать, что если возможно установить один субъект, для которого отходы есть благо, равно как и обращение с ними, то наличествует и возможность отнесения данной категории к системе объектов гражданских прав.

Целесообразным представляется обращение к приведенной Е.Ю. Андреевой классификации подходов к пониманию объектов гражданских прав в гражданской доктрине. Ею анализируется пять подходов и указывается 
на то, что «теоретической основой исследования вопросов гражданского оборота объектов гражданских прав, несомненно, является теория объектов гражданских прав и объектов прав в целом» [1, с. 246].

\section{Категории «объект»и «отходы»}

\section{в гражданском обороте}

При исследовании системы как совокупности составляющих частей, являющихся однородными по своим задачам, целесообразно рассматривать таковые как определяющие в соотнесении отходов к объектам гражданских прав.

В своих работах Е.Ю. Андреева указывает на то, что «М.М. Агарков, например, под объектом гражданского правоотношения понимал, в первую очередь, вещь. А. Голунский и М. Строгович подразделяют объекты прав на вещи и иные ценности, действия и воздержание от действий. Я.М. Магазинер сущность всякого правоотношения находит в том, что объектом всякого права является чужое действие. О.С. Иоффе была введена теория нескольких уровней объекта правоотношений» [1, c. 246].

Р.Ф. Галеева приводит только три подхода в определении объектов гражданских прав: «согласно первому объектом гражданских прав является то, на что направлены права и обязанности субъектов. В соответствии со вторым подходом объектами прав признается то, по поводу чего возникает гражданское правоотношение. Сторонники третьего подхода под объектами понимают то, на что правомочие и обязанность оказывают или могут оказать воздействие» [5, с. 91].

По мнению А.П. Анисимова, А.Я. Рыженкова, А.Ю. Чикильдиной, «объекты гражданских прав - это одна из важнейших проблем в цивилистической науке» [2, с. 8]. Согласно их позиции «расширение круга объектов гражданских прав происходит не только в русле правовых реформ, но и с развитием науки и техники» $[2$, с. 8$]$.

Широкий спектр научных позиций создает предпосылки для необходимости осуществления выбора между рассмотрением объекта гражданских прав как: 1) блага; 2) поведения участников правоотношений; 3) поведения участников общественных отношений по поводу благ; 4) правового режима; 5) совокупности юридических и материальных отношений, определяющих объект.

При наличии научной дискуссии по поводу того, что же понимать под объектом гражданских прав, весьма значимой и применимой на современном этапе видится позиция В.А. Витушко, указывающего, что следует все-таки рассматривать объект как «то, на что направлены интересы субъектов правоотношений» [4, с. 306].

Первичность интереса, факт наличия его направленности на объекты со стороны субъекта как носителя прав и обязанностей представляются актуальными. Если ранее нормативно отходы именовались мусором и не всегда рассматривались как благо, то сегодня бесспорным представляется, что предметы, утратившие свои потребительские свойства, выступают объектом интереса не только физических лиц, но и государства.

Обращаясь же к классификации объектов гражданских прав, установленной Гражданским кодексом Республики Беларусь [6], целесообразным видится отнесение отходов как предметов к категории вещей, тому, на что направлен интерес субъекта.

При этом само стремление возможно рассматривать как благо. Поскольку согласно Аристотелю «всякое искусство и всякое учение, а равным образом поступок (praxis) и сознательный выбор, как принято считать, стремятся к определенному благу» [3, с. 41], «цель эта есть собственно благо (tagathon), то есть наивысшее благо (toariston)» [3, с. 42].

В системе современных научных достижений частноправового характера в Республике Беларусь рассмотрение отходов как объектов гражданских прав представляется обоснованным осуществлять исходя из их свойств, закрепленных на законодательном уровне.

\section{Юридическое закрепление признаков отходов}

Согласно Закону Республики Беларусь от 20 июля 2007 г. № 271-3 «Об обращении с отходами» отходы отнесены к категории веществ и предметов [7]. При этом вещество 
представляет собой составляющий элемент физического тела, а предмет - всякое материальное выражение вещи. В то же время сама вещь в обороте рассматривается как отдельный предмет.

Оперируя в правоприменительной практике Республики Беларусь таким определением отходов, которое указывает на них как на вещества или предметы, образующиеся в процессе осуществления экономической деятельности, жизнедеятельности человека и не имеющие определенного предназначения по месту их образования либо утратившие полностью или частично свои потребительские свойства [7], представляется обоснованным рассматривать их как объекты, обладающие физической, телесной характеристикой. Данная характеристика настолько широко представлена, что вызвала классификацию отходов по классам опасности и введение в действие классификатора отходов, относящего их к определенной категории в зависимости от происхождения, агрегатного состояния, степени опасности, возможности использования.

Так, в соответствии с Законом Республики Беларусь № 271-3 отходы подразделяются: 1) на отходы производства и отходы потребления; 2) твердые отходы и жидкие отходы; 3) опасные отходы и неопасные отходы; 4) вторичные материальные ресурсы и иные отходы производства и потребления [7].

В Республике Беларусь существует также классификация, установленная Министерством природных ресурсов и охраны окружающей среды, согласно которой отходы подразделяются: 1) на отходы растительного и животного происхождения; 2) отходы минерального происхождения; 3) отходы химических производств и производств, связанных с ними; 4) медицинские отходы; 5) отходы (осадки) водоподготовки котельно-теплового хозяйства и питьевой воды, очистки сточных, дождевых вод и использования воды на электростанциях; 6) отходы жизнедеятельности населения и подобные им отходы производства [9].

Приведенные наименования позволяют, как правило, определить, в результате какого процесса они образовались: 1) экономическая деятельность; 2) жизнедеятельность человека.

При этом существует понятие «коммунальные отходы». Согласно Закону Республи- ки Беларусь № 271-3 стоящие отдельно от иных видов отходов и указывающие на необходимость дополнительного анализа классификации отходов в связи с употребляемой формулировкой «отходы, в том числе коммунальные отходы, разделяются по видам» [7].

При рассмотрении системы объектов гражданских прав как саморазвивающейся системы наличие классификации отходов представляется как показатель наличия системы, существующей на ином уровне саморегуляции. При этом базой системы, вне которой не может существовать система классификации отходов, является системность, используемая в отношении объектов гражданских прав.

Так, качественные характеристики отходов позволяют относить их к различным видам объектов гражданских прав, таких как: 1) находящиеся в свободном обороте; 2) оборот которых ограничен; 3) изъятые из оборота. При этом отходы есть категория вещей, рассматриваемая Н.С. Михайловой со ссылкой на О.С. Иоффе «как определенная часть живой и неживой природы» [8, с. 179].

Накопленные и сгруппированные сведения и представления о свойствах вещей в целом определили правовую регламентацию порядка регулирования их обращения. Гражданско-правовая доктрина и гражданское законодательство представляются основой для регулирования обращения отходов в Республике Беларусь как объектов, обладающих следующими свойствами: 1) отсутствие определенного предназначения по месту образования; 2) утрата потребительских свойств; 3) твердые; 4) жидкие; 5) результат производства; 6) результат потребления; 7) опасные; 8) неопасные и иные, перечень которых, как следует из вышеуказанного, достаточно широк. Важным является то, что каждый из нормативно закрепленных признаков указывает на то, что отходы в гражданском обороте подлежат правовой регламентации, в том числе исходя из характеристик объектов оборота: движимые и недвижимые вещи, делимые и неделимые, простые и сложные и т. д.

Излишним представляется указание на особое присутствие в классификации коммунальных отходов - это отходы потребления и отходы производства, включенные в утверж- 
даемый Министерством жилищно-коммунального хозяйства Республики Беларусь перечень отходов, относящихся к коммунальным отходам, удаление которых организуют местные исполнительные и распорядительные органы [7], оно не содержит особых характеристик, дающих основания не применять к ним основания классификации.

\section{Выводы}

Система объектов гражданских прав представляет собой особый порядок в понимании сути объектов через определение основных критериев, являющихся едиными для расположения и связи действий субъектов в отношении данных объектов. Целесообразным представляется отнесение отходов к объектам с позиции понимания их содержания: на что направлен интерес субъектов правоотношений. Открытым и дискуссионным остается вопрос отнесения всей совокупности отходов к категории вещей, поскольку вещества (выбросы и подобные им результаты производства и жизнедеятельности) нельзя по их биологическим и химическим характеристикам определить как вещи. Безусловным остается наличие группы отходов - предметов, которые, являясь вещами, согласно законодательству Республики Беларусь, не имеющими определенного предназначения по месту образования либо утратившими полностью или частично свои потребительские свойства [7], присутствуют в гражданском обороте.

Свойства отходов, выявленные и являющиеся критериями для определения вида и места в классификации, представляется целесообразным рассматривать как основания для отнесения к различным группам объектов гражданских прав в зависимости от оборотоспособности.

Совершенствование правового механизма группирования отходов с учетом их характеристик как вещей в системе объектов гражданских прав, обладающих определенными качествами, свойствами, не позволяющими их использовать по месту образования либо дающими основания считать утратившими потребительское назначение, а также поиск иных определяющих сути отходов позволят усовер- шенствовать порядок гражданско-правового регулирования обращения отходов в Республике Беларусь.

Предлагается исключить указание на коммунальные отходы и ч. 1 ст. 15 Закона Республики Беларусь «Об обращении с отходами» изложить в следующей редакции: «1. Отходы разделяются по видам в зависимости от:

1.1. происхождения - на отходы производства и отходы потребления;

1.2. агрегатного состояния - на твердые отходы и жидкие отходы;

1.3. степени опасности - на опасные отходы и неопасные отходы;

1.4. возможности их использования - на вторичные материальные ресурсы и иные отходы производства и потребления».

\section{СПИСОК ЛИТЕРАТУРЫ}

1. Андреева, Е. Ю. Проблемы оборота объектов гражданских прав в современной науке и юридической практике / Е. Ю. Андреева // Известия Российского государственного педагогического университета им. А.И. Герцена. - 2011. - № 131. - С. 245-255.

2. Анисимов, А. П. Объекты гражданских прав : новые векторы правового регулирования / А. П. Анисимов, А. Я. Рыженков, А. Ю. Чикильдина // Вестник Волгоградского государственного университета. Серия 5, Юриспруденция. - 2013. - № 4 (21). - С. 8-14.

3. Аристотель. Этика / Аристотель. - М. : Астрель, 2012. -492 c.

4. Витушко, В. А. Курс гражданского права: Общая часть. Т. 1 / В. А. Витушко. - Минск : БГЭУ, 2001. $-414 \mathrm{c}$.

5. Галеева, Р. Ф. Сущность объектов гражданских прав / Р. Ф. Галеева // Ученые записки Казанского государственного университета. - 2009. T. 151. - C. 91-97.

6. Гражданский кодекс Республики Беларусь от 7 дек. 1998 г. № 218-3 : принят Палатой представителей 28 окт. 1998 г. : одобр. Советом Респ. 19 нояб. 1998 г. : в ред. Закона Респ. Беларусь от 30 дек. 2015 г. // ЭТАЛОН. Законодательство Республики Беларусь. - Минск, 2017.

7. Закон Республики Беларусь «Об обращении с отходами〉 от 20 июля 2007 г. № 271-3 : в ред. от 15 июля 2015 г. № 288-3// ЭТАЛОН. Законодательство Республики Беларусь. - Минск, 2017.

8. Михайлова, Н. С. Система объектов гражданских прав и место вещей в этой системе / Н. С. Михайлова // Известия Российского государ- 
ственного педагогического университета им. А.И. Герцена. - 2007. - № 33. - С. 177-180.

9. Постановление Совета министров Республики Беларусь «Об утверждении классификатора отходов, образующихся в Республике Беларусь» от 8 нояб. 2007 г. № 85 : в ред. постановления Совета министров Респ. Беларусь от 31 дек. 2010 г. // ЭТАЛОН. Законодательство Республики Беларусь. Минск, 2017.

\section{REFERENCES}

1. Andreeva E.Yu. Problemy oborota obyektov grazhdanskikh prav $v$ sovremennoy nauke i yuridicheskoy praktike [Problems of Turnover of Civil Rights Objects in Modern Science and Legal Practice]. Izvestiya Rossiyskogo gosudarstvennogo pedagogicheskogo universiteta im. A.I. Gertsena, 2011, no. 131, pp. 245-255.

2. AnisimovA.P., RyzhenkovA.Ya., ChikildinaA.Yu. Obyekty grazhdanskikh prav: novye vektory pravovogo regulirovaniya [Objects of Civil Rights: New Vectors of Legal Regulation]. Vestnik Volgogradskogo gosudarstvennogo universiteta. Seriya 5, Yurisprudentsiya [Science Journal of Volgograd State University. Jurisprudence], 2013, no. 4 (21), pp. 8-14.

3. Aristotel. Etika [Aristotle. Ethics]. Moscow, Astrel Publ., 2012. 492 p.

4. Vitushko V.A. Kurs grazhdanskogo prava: Obshchaya chast. T. 1 [Course of Civil Law: General Part. Vol. 1]. Minsk, BGEU Publ., 2001. 414 p.

5. Galeeva R.F. Sushchnost obyektov grazhdanskikh prav [The Essence of Civil Rights Objects]. Uchenye zapiski Kazanskogo gosudarstvennogo universiteta, 2009, vol. 151, pp.91-97.
6. Grazhdanskiy kodeks Respubliki Belarus ot 7 dek. 1998 g. № 218-Z: prinyat Palatoy predstaviteley 28 okt. 1998 g.: odobr. Sovetom Resp. 19 noyab. 1998 g.: v red. Zakona Resp. Belarus ot 30 dek. 2015 g. [The Civil Code of the Republic of Belarus of December 7, 1998 no. 218-Z: adopted by the House of Representatives on October 28, 1998: approved by the Council of the Republic of Belarus on November 19, 1998 (ed. of the Law of the Republic of December 30, 2015]. ETALON. Zakonodatelstvo Respubliki Belarus [Etalon. Legislation of the Republic of Belarus]. Minsk, 2017.

7. Zakon Respubliki Belarus «Ob obrashchenii s otkhodami» ot 20 iyulya 2007 g. № 271-Z : v red. ot 15 iyulya 2015 g. № 288-Z [The Law of the Republic of Belarus "On Waste Management" of July 20, 2007 no. 271-Z (ed. of July 15, 2015 no. 288-Z)]. ETALON. Zakonodatelstvo Respubliki Belarus [Etalon. Legislation of the Republic of Belarus]. Minsk, 2017.

8. Mikhaylova N.S. Sistema obyektov grazhdanskikh prav i mesto veshchey v etoy sisteme [The System of Civil Rights Objects and the Place of Things in this System]. Izvestiya Rossiyskogo gosudarstvennogo pedagogicheskogo universiteta im. A.I. Gertsena, 2007, no. 33, pp. 177-180.

9. Postanovlenie Soveta ministrov Respubliki Belarus «Ob utverzhdenii klassifikatora otkhodov, obrazuyushchikhsya v Respublike Belarus» ot 8 noyab. 2007 g. № 85 : v red. postanovleniya Soveta ministrov Resp. Belarus ot 31 dek. 2010 g. [The Decree of the Council of Ministers of the Republic of Belarus "On Approval of the Classifier of Wastes Generated in the Republic of Belarus" of November 8, 2007 no. 85 (ed. of the Decree of the Council of Ministers of the Republic of Belarus of December 31, 2010]. ETALON. Zakonodatelstvo Respubliki Belarus [Etalon. Legislation of the Republic of Belarus]. Minsk, 2017.

\section{Information about the Author}

Anna A. Kisel, Doctoral Student, Department of Civil Law Disciplines, Belarusian State University of Economics, Prosp. Partizansky, 26, 220070 Minsk, the Republic of Belarus, 2_9_7_9@mail.ru.

\section{Информация об авторе}

Анна Антоновна Кисель, соискатель кафедры гражданско-правовых дисциплин, Белорусский государственный экономический университет, просп. Партизанский, 26, 220070 г. Минск, Республика Беларусь, 2_9_7_9@mail.ru. 